\title{
Comparing the Treatment Outcomes of Tuberculosis Patients in Private Clinic with Governmental Health Centre in Jimma City, Ethiopia.
}

Eyob Girma Abera ( $\sim$ eyobgirma840@gmail.com )

Research article

Keywords: tuberculosis, Treatment outcome, Comparing, Governmental health center, Private clinic

Posted Date: November 6th, 2019

DOI: https://doi.org/10.21203/rs.2.16877/v1

License: (c) (1) This work is licensed under a Creative Commons Attribution 4.0 International License.

Read Full License 


\section{Comparing the Treatment Outcomes of Tuberculosis Patients in Private Clinic with Governmental Health Centre in Jimma City, Ethiopia.}

Author Name: Eyob Girma Abera

Address: 636 of Zijing Apartment Building 22

Tsinghua University, Haidian District, Beijing ,100084

Email: eyobgirma840@gmail.com

Cell-Phone- +251910093601

Co-author: Cheng Feng (Professor), Public Health Research Center,

Tsinghua University, Beijing, China.

Word count: 5103 


\begin{abstract}
Background: Tuberculosis is a common and often deadly infectious disease caused by various strains of mycobacterium, usually mycobacterium tuberculosis in humans. Tuberculosis has long been major cause of morbidity and mortality particularly where the diagnostic and control program is not far extended.

Objective: - To compare the treatment outcomes and to describe the social demographic factors associated with Tuberculosis patient in private clinic with governmental health centre in Jimma city, Ethiopia from September 12, 2007 to September 10, 2017.

Methods and Materials: - A ten years retrospective systemic record review was conducted to compare the treatment outcomes and to describe the social demographic factors associated with Tuberculosis patient in private clinic with governmental health centre in Jimma city, Ethiopia from September 12, 2007 to September 10, 2017. Data was collected by using questionnaire formats. Since all serial numbers of the patients were used no sampling technique was needed. Finally data was analyzed by SPSS/EPI INFO.

Result: The present study revealed that within ten years duration private clinic gives anti-TB treatment coverage for 582 patients whereas governmental clinic gives for 510 patients.

The treatment success rate of the private clinic is $98.1 \%$ which is 1.03 fold than the governmental health center $(95.3 \%)$. Governmental health center defaulting rate was triple fold of the private clinic $4.1 \%$ and $1.2 \%$ receptively, while the treatment failure of private clinic was $0.2 \%$, but no treatment failure in governmental health center.

Conclusion and Recommendation-Age, educational level and the types of TB diagnosis and treatment outcome of the patients were statistically associated in both sectors. Better counseling and awareness about the disease should have to be given for every anti-TB treatment receiving patients despite of their educational level and occupational status in both sectors.
\end{abstract}

Keywords: Tuberculosis, Treatment outcome, Comparing, Governmental health center, Private clinic 


\section{Strength of the Study}

- The study helps to describe the association of social demographic factors with Tuberculosis patients and their treatment outcome.

- This study is useful to assess and to compare the treatment outcomes of tuberculosis patients in government health centre and private clinic since there is no previous similar study in the area.

- To compare the extent of tuberculosis treatment burden which handled between the sectors.

- Further, more the findings will act as baseline for further studies more over finding will help to formulate strategies to give the appropriate tuberculosis care and to sensor what really affect the outcome.

- Also how private clinics are helping the government health institutions by providing antiTB regime relative to the similar catchment population with the government and what is behind on the numbers difference value.

\section{Limitation of The Study}

- Data accuracy is under question with some incomplete subjects since it is a secondary data.

- The sources of this study is Jimma health center and Jimma medium clinic records; hence, the result may lack external validity.

- Lack of stable internet from Ethiopia during data collection. 


\section{Chapter 1: Background}

TB is a major public health problem throughout the world and one of the leading causes of death worldwide. One third of the world's population is infected with TB [1]. The foundation of the current global TB strategy began in the 1990s, when the increasing trends of TB led to the creation of directly observed treatment- short course (DOTS) strategy. The multidimensional DOTS framework has been implemented in 184 countries and over 132 million patients have been treated with DOTS resulting in more than 125 million being cured $[\mathbf{2 , 3 , 4 , 5 ] . ~ I n ~ 2 0 1 6 , ~} 10.4$ million people around the world became sick with TB disease. There were 1.7 million TB-related deaths worldwide. TB is a leading killer of people who are HIV infected, in 2016, $40 \%$ of HIV deaths were due to TB [6]. TB incidence falls $1.5 \%$ per year globally but challenged by the emergence and increase in drug resistance TB worldwide and association of TB and HIV infections also TB control has been hindered with poor treatment outcome up to death and TB still remains one of the world's major threat to public health $[7,26]$.

Tuberculosis is the still problem in Ethiopia, the trend of TB incidence is still rise in contract the global trend is falling. The Emergence of resistance TB and high prevalence of MDR TB in Ethiopia is one threatening and drawback factor for TB control program. We can prevent the emergence of acquired resistance by using the good practice which is the simplest and easiest way to prevent the complicated and serious disease [8]. Ethiopia ranks 3rd in Africa and 8th among the 22 highest tuberculosis (TB) burdened countries in the world [7]. In 2016/2017 TB case notification rate is 123 per 100, 000 population. $40 \%$ bacteriology confirmed new and relapse, $29 \%$ clinically diagnosed new, $31 \%$ diagnosed EPTB and previously treated TB accounts $4.2 \%$ of the total TB case detected. TB case detection rate of $64 \%$, treatment success rate of $94 \%$, and cure rate of $85 \%$ [9-10]. The burden of TB is the highest in Oromia region according to the national 2017 report, registered 68,106 cases of TB [9-10]. For drug resistant TB, Ethiopia is one of the 27 high MDR-TB countries; it is ranked $15^{\text {th }}$ with more than 5000 estimated MDR-TB patients each year. There are a cumulative total of 3,767 MDR TB patients were enrolled in second line drug (SLD), in 2017, 706 RR/MDR-TB cases are diagnosed and enrolled to second line anti TB drug; the treatment success rate of MDR TB reached 71.3\% [10-11]. 
This study is useful to assess and to compare the treatment outcomes of tuberculosis patients in government health centre and private clinic which helps to identify the extent of tuberculosis treatment burden which handled between the sectors. Further, more the findings will act as baseline for further studies more over finding will help to formulate strategies to give the appropriate tuberculosis care and to sensor what really affect the outcome. 


\section{Chapter 2: Methods}

\section{1: Study Area Population}

The study was being conducted in Jimma health center and Jimma medium clinic. The public health center gives service for 42,164 populations in its catchments area and the private medium clinic has 40,104 population in its catchment area. According to 2017 Jimma town health bureau, the town has 1 specialized hospital , 1 zonal hospital, 1 private hospital, 4 health center, 2 NGO, 2 health post and 28 private clinics. Among them TB treatment is available in 4 private clinics, 1 private hospital, 2 NGOs and the rest all governmental health sectors [12-13].

\section{2: Study Design}

A ten year retrospective systemic record review was conducted in Jimma health center and Jimma medium clinic. All patient who took anti-TB treatment from the registration used Since September 12, 2007 to September 10, 2017 included in the study. The survey included the following: Age Sex Occupational status, Educational status, Treatment outcome, Types of TB, Category of patients. Data was collected by the trained and assigned TB and leprosy unit personnel in the private and public health sectors.

\subsection{1: Treatment Outcome Definition}

TB treatment outcome categories were defined according to $\mathrm{WHO}$ and the International Union against Tuberculosis and Lung Disease guideline [14]. WHO defines treatment success as the sum of patients who are cured and those who have completed treatment? In line with WHO criteria, treatment outcomes were categorized into:

1. Successful outcome- if PTB patients were cured (i.e., negative smear microscopy at the end of treatment and on at least one previous follow-up test) or completed treatment with resolution of symptoms.

2. Unsuccessful outcome - if treatment of PTB patients resulted in treatment failure (i.e., remaining smear-positive after 5 months of treatment), default (i.e., patients who interrupted their treatment for two consecutive months or more after registration), or death. 


\section{3: Statistical Analysis}

The collected data was checked for completeness and analyzed by using IBM version 23 SPSS/EPI INFO. Relationships between treatment outcomes and potential predictor variables were assessed using multivariate logistic regression model. 


\section{Chapter 3: Result}

\section{1: Socio-Demographic and Clinical Characteristics of the Patients with the TB Trend}

A total of 510 and 582 patients were followed anti TB treatment in the governmental and private clinic respectively. The majority of the patients in governmental clinic were females constituted 53.7\% ( $\mathrm{n}=274)$ and Males in private clinic constituted $50.9 \%(\mathrm{n}=298)$. In both sectors majority of patients were between the age 15-49 years which accounted for $82.3 \%(n=420)$ in governmental health center and $74.2 \%(n=432)$ in private clinic with the mean age of 34.4 and 32.4 years respectively. In both sectors new patients were the majority number $91.2 \%(\mathrm{n}=465)$ and $96.9 \%(n=564)$ where as $3.1 \%(n=16)$ and $1.0 \%(n=6)$ were transferred in, $3.7 \%(n=19)$ and $0.5 \%(n=3)$ were relapse, $2.0 \%(n=10)$ and $1.5 \%(n=9)$ were others in governmental health center and private clinic respectively. Regarding category of $\mathrm{TB}$, in both sectors Extra pulmonary tuberculosis constituted similar number $48.4 \%(\mathrm{n}=247)$ in governmental health center and 41.8 $\%(\mathrm{n}=243)$ in private clinic, while smear negative pulmonary tuberculosis was $3.9 \%(\mathrm{n}=20)$ in governmental health center and $35.1 \%(\mathrm{n}=204)$ in private clinics. Smear positive pulmonary tuberculosis in governmental health center is higher than the private clinic $47.6 \%(n=243)$ and $23.2 \%(\mathrm{n}=135)$ respectively. 92 patients had the data for occupational status and educational level, 50 patients were from the governmental health center and 42 from the private clinic which have been taken from March 12 - August 11 and from September 4 - April 3, 2015 respectively. The majority of educational level was higher educated patients which is similar in both sectors $34 \%$ $(\mathrm{n}=17)$ and $35.7 \%(\mathrm{n}=15)$. Occupational status of governmental health center patients were governmental employee $20 \%(\mathrm{n}=10)$ whereas $21.4 \%(\mathrm{n}=9)$ of private clinic patients were students. (Table 1) 
Table1: Distribution of Sex, Age, educational level, occupational status, Category of patients and Types of TB diagnosis in Jimma health center and Jimma medium clinic, Jimma town, Oromia region, south west Ethiopia from Sept 11, 2006 - Sept 10, 2017.

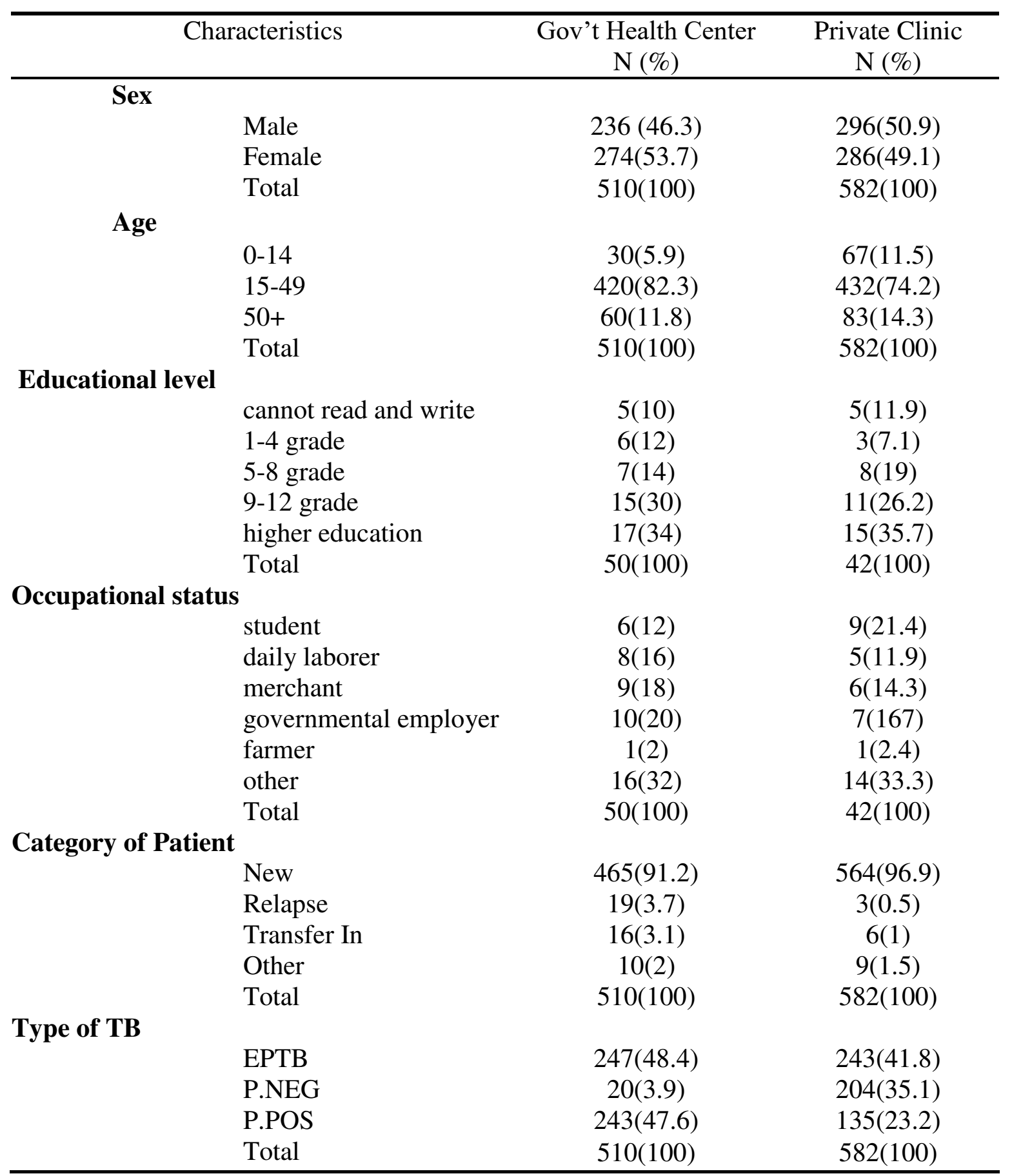




\subsection{1: Trend of Tuberculosis Case}

The ten years all form of TB trend was analyzed and the private clinic anti TB treatment coverage was decreased through years which reaches to 2\% on Sept 10, 2017 from 20\% of Sept 2009, while for the past four years Sept 12, 2013 to Sept 10, 2017 the governmental clinic shows revitalization of anti TB treatment coverage. (Figure 1)

\section{2: Treatment Outcome of TB}

The ten years treatment outcome for 1092 patients from both sectors were analyzed. Hence, the majority of patients were completed the anti TB treatment in both sectors $49.2 \%(n=251)$ in governmental health center and $76.3 \%(n=444)$ in private clinic also the cure rate was $46.1 \%($ $\mathrm{n}=235)$ and $21.8 \%(\mathrm{n}=127)$ respectively. Whereas the default rate was $4.1 \%(\mathrm{n}=21)$ and $1.2 \%$ $(\mathrm{n}=7)$ in governmental and private sectors respectively. In both sectors 3 patients were died. No treatment failure patients documented in governmental health center whereas $0.2 \%(n=1)$ in private clinic. The overall treatment success rate of the private clinic is higher than the governmental health center $98.1 \%(n=571)$ and $95.3 \%(n=486)$ respectively. Also the overall unsuccessful treatment outcome rate of governmental health center was $4.7 \%(\mathrm{n}=24)$ which is higher than $1.9 \%$ $(\mathrm{n}=11)$ of the private clinic. (Figure 2$)$

Among the sectors the majority of patients under the age of 15-49 years old is completed the treatment in private clinic than the governmental health center $72.7 \%(n=314)$ and $46 \%$ $(n=193)$ respectively. Female patients were more defaulter than male patients in both sectors $4.7 \%$ (13) in governmental and $1.7 \%$ (5) in private clinic. Three patients are died in all types of TB and they were new in governmental health center while Two EPTB and one P.NEG patients are died those were New and transfer in respectively. $96.7 \%(n=235)$ smear positive pulmonary TB patients were cured in governmental health center while $90.4 \%(n=122)$ smear positive pulmonary TB patients were cured in private medium clinic. (Table 2)

Table 2: Distribution of age, sex, educational level, occupational status, types of TB and category of patients in relation to their treatment outcome in Jimma health center and Jimma medium clinic, Jimma town, Oromia region, south west Ethiopia from Sept 11, 2006 - Sept 10, 2017. 
Characteristics Treatment Outcome (\%)

Completed Defaulter Cured Died $\quad$ Failure Total (\%)

Gov't Private Gov't private Gov't Private Gov't Private Private Gov't Private

Age

$\begin{array}{clllllllllll}0-14 & 26(86.7) & 63(94) & 0 & 0 & 4(13.3) & 4(6) & 0 & 0 & 0 & 30(5.9) & 67(11.5) \\ 15-49 & 193(46.0) & 314(72.7) & 19(4.5) & 6(1.4) & 206(49) & 110(25.5) & 2(0.5) & 1(0.2) & 1(0.2) & 420(82.3) & 432(74.2) \\ 50+ & 32(53.3) & 67(80.7) & 2(3.3) & 1(1.2) & 25(41.7) & 13(15.7) & 1(1.7) & 2(2.4) & 0 & 60(11.8) & 83(14.3) \\ \text { Total } & 251 & 444 & 21 & 7 & 235 & 127 & 3 & 3 & 1 & 510 & 582\end{array}$

Sex

\begin{tabular}{|c|c|c|c|c|c|c|c|c|c|}
\hline Male & $107(45.3)$ & $219(74)$ & $8(3.4)$ & 2(7) & $119(50.4) 72(24.3)$ & $2(0.8)$ & $2(0.7)$ & $1(0.3)$ & $236(46.3) 296(50.9)$ \\
\hline Female & $144(52.6)$ & $225(78.7)$ & $13(4.7)$ & $5(1.7)$ & $116(42.3) 55(19.2)$ & $1(0.4)$ & $1(0.3)$ & 0 & $274(53.7) 286(49.1)$ \\
\hline Total & 251 & 444 & 21 & 7 & $235 \quad 127$ & 3 & 3 & 1 & 510 \\
\hline
\end{tabular}

Educational level

$\begin{array}{clllllllllll}\text { Illiterate } & 1(20) & 1(20) & 4(80) & 2(40) & 0 & 0 & 0.0 & 2(40) & 0 & 5(10) & 5(11.9) \\ \text { 1-4 grade } & 4(66.7) & 2(66.7) & 1(16.7) & 1(33.3) & 1(16.7) & 0 & 0.0 & 0 & 0 & 6(12) & 3(7.1) \\ \text { 5-8 grade } & 6(85.7) & 6(75) & 0 & 1(12.5) & 1(14.3) & 1(12.5) & 0.0 & 0 & 0 & 7(14) & 8(19) \\ \text { 9-12 grade } & 13(86.7) & 10(90.9) & 1(6.7) & 1(9.1) & 1(6.7) & 0 & 0.0 & 0 & 0 & 15(30) & 11(26.2) \\ \text { gher education } & 12(70.6) & 5(33.3) & 0 & 0 & 5(29.4) & 10(66.7) & 0.0 & 0 & 0 & 17(34) & 15(35.7) \\ \text { Total } & 36 & 24 & 6 & 5 & 8 & 11 & 0.0 & 2 & 0 & 50 & 42\end{array}$

\section{Occupational}

status

$\begin{array}{llllllllllll}\text { student } & 5(83.3) & 7(77.8) & 0 & 0 & 1(16.7) & 2(22.2) & 0.0 & 0 & 0 & 6(12) & 9(21.4)\end{array}$

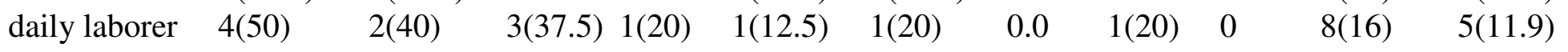

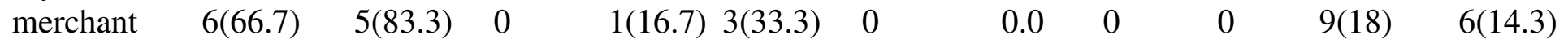

$\begin{array}{llllllllll}\text { Gov't employer } 9(90) & 4(57.1) & 0 & 1(14.301(10) & 2(28.6) & 0.0 & 0 & 0 & 10(20) & 7(16.7)\end{array}$

$\begin{array}{clllllllllll}\text { farmer } & 1(100) & 1(100) & 0 & 0 & 0 & 0 & 0.0 & 0 & 0 & 1(2) & 1(2.4) \\ \text { other } & 11(68.8) & 5(35.7) & 3(18.8) & 2(14.3) & 2(12.5) & 6(42.90 & 0.0 & 1(7.1) & 0 & 16(32) & 14(33.3) \\ \text { Total } & 36 & 24 & 6 & 5 & 8 & 11 & 0.0 & 2 & 0 & 50 & 42\end{array}$

Types of TB

\begin{tabular}{|c|c|c|c|c|c|c|c|c|c|c|}
\hline ЕРТВ & $233(94.3)$ & $237(97.5)$ & ) $13(5.3)$ & $2(0.8)$ & 0 & $2(0.8)$ & $1(0.4)$ & $2(0.8)$ & 0 & $247(48.4) 243(41.8)$ \\
\hline P.NEG & $16(80)$ & 198(97.1) & $3(15)$ & $2(1)$ & 0 & $3(1.5)$ & $1(5)$ & $1(0.5)$ & 0 & $20(3.9) \quad 204(35.1)$ \\
\hline P.PC & $2(0.8)$ & $9(6.7)$ & $5(2.1)$ & $3(2.2)$ & 235(96.7) & $122(90.4)$ & $1(0.4)$ & 0 & $1(0.7)$ & $243(47.6) 135(23.2)$ \\
\hline & & 444 & 21 & & & & & & & \\
\hline
\end{tabular}

Patient Category

\begin{tabular}{|c|c|c|c|c|c|c|c|c|c|c|c|}
\hline New & 231(49.7) & 434(77) & $17(3.7)$ & $6(1.1)$ & 214(46) & $121(21$. & $3(0.6)$ & $2(0.4)$ & 1 & 465(91. & $564(96.9)$ \\
\hline Relapse & $4(21.1)$ & 1(33.3) & $1(5.3)$ & $1(33.3)$ & $14(73.7)$ & $1(33.3)$ & 0 & 0 & 0 & $19(3.7)$ & $3(0.5)$ \\
\hline ransfer In & $10(62.5)$ & $3(50)$ & $2(12.5)$ & 0 & $4(25)$ & $2(33.3)$ & 0 & $1(16.7)$ & 0 & $16(3.1)$ & $6(1)$ \\
\hline Other & $6(60)$ & $6(66.7)$ & 1(10) & 0 & $3(30)$ & $3(33.3)$ & 0 & 0 & 0 & $10(2)$ & $9(1.5)$ \\
\hline Total & 251 & 444 & 21 & 7 & 235 & 127 & 3 & 3 & 1 & 510 & 582 \\
\hline
\end{tabular}




\section{3: Treatment Outcome and Its Associated Predictors}

Multivariate logistic regression analysis was carried out to predict factors affecting the treatment outcome with socio-demographic and clinical risk factors including age, sex, educational level, and occupational status, the type of TB and treatment category of patients. The proportion recorded on multivariate logistic model as having an unsuccessful treatment outcome varied by age group, educational level and the type of TB.

The risk of unsuccessful treatment outcome was 1.26 (95\% CI: 0.96-2.24) and 2.16 (95\% CI: 0.67-3.09) times higher among 15-49 years old TB patients in governmental and private clinics respectively compared to those aged 0-14 years and over 50 years old patients. In other predictor the illiterate patients in the governmental health center had 3.63 (95\%CI: 1.98-5.45) times and 2.73 (95\%CI: 1.18-4.31) in private clinic experience greater risk of unsuccessful treatment outcome compared to the literate patients. The governmental health center had higher Poor treatment outcome in EPTB type of patients ( $\mathrm{AOR}=2.12$, CI 1.02-3.67) than the private clinic $(\mathrm{AOR}=1.84, \mathrm{CI} 1.01-3.78)$ which compares with their counterparts of type TB. Sex, occupational status and category of patients did not show any statistically significant association with unsuccessful treatment outcome in the multivariate analysis (Table 3).

Table 3. Logistic regression analyses of factors associated with treatment outcome of TB patients in Jimma health center and Jimma medium clinic, Jimma town, Oromia region, south west Ethiopia from Sept 11, 2006 - Sept 10, 2017. 


\begin{tabular}{|c|c|c|c|c|c|c|c|c|}
\hline \multirow[t]{2}{*}{ Characteristics } & \multicolumn{2}{|l|}{$\mathrm{N}(\%)$} & \multicolumn{4}{|c|}{$\mathrm{N}(\%)$ of Unsuccessful AOR(95\%CI) } & \multicolumn{2}{|l|}{ p-value } \\
\hline & Gov’t & Private & Gov't & Private & Gov’t & Private & Gov't & Private \\
\hline \multicolumn{9}{|l|}{$\overline{\text { Age }}$} \\
\hline $0-14$ & $30(5.9)$ & $67(11.5)$ & 0 & 0 & - & - & - & - \\
\hline $15-49$ & $420(82.3)$ & $432(742)$ & $21(5)$ & $8(1.8)$ & $1.26(0.96-2.24)$ & $2.16(0.67-3.09)$ & 0.016 & 0.013 \\
\hline $50+$ & $60(11.8)$ & $83(14.3)$ & $3(5)$ & $3(3.6)$ & $1.00($ reference) & 1 (Reference) & Reference & Reference \\
\hline \multicolumn{9}{|c|}{ 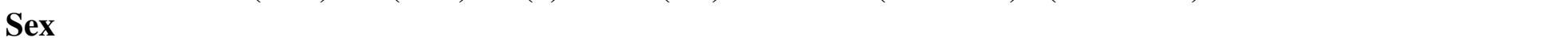 } \\
\hline Male & $236(46.3)$ & $296(50.9)$ & $10(4.2)$ & $5(8)$ & $0.86(0.72-1.31)$ & ) $1.34(0.51-2.98)$ & 0.239 & 0.934 \\
\hline Female & $274(53.7)$ & $286(49.1)$ & $14(5.1)$ & $6(2)$ & $1.00($ reference $)$ & $1($ Reference $)$ & Reference & Reference \\
\hline \multicolumn{9}{|l|}{$\begin{array}{l}\text { Educational } \\
\text { level }\end{array}$} \\
\hline Illiterate & $5(10)$ & $5(11.9)$ & $4(80)$ & $4(80)$ & $3.63(1.98-5.45)$ & $2.73(1.18-4.31)$ & 0.019 & 0.009 \\
\hline 1-4 grade & $6(12)$ & $3(7.1)$ & $1(16.7)$ & $1(33.3)$ & $1.61(0.89-2.34)$ & $1.92(0.82-2.63)$ & 0.027 & 0.005 \\
\hline 5-8 grade & $7(14)$ & $8(19)$ & $0(0)$ & $1(12.5)$ & - & $1.03(0.72-2.66)$ & - & 0.003 \\
\hline $9-12$ grade & $15(30)$ & $11(26.2)$ & $1(6.7)$ & $1(9.1)$ & $1.00($ reference $)$ & $0.78(0.38-2.89)$ & Reference & 0.002 \\
\hline $\begin{array}{c}\text { higher } \\
\text { education }\end{array}$ & $17(34)$ & $15(35.7)$ & $0(0)$ & 0 & - & 1(Reference) & - & Reference \\
\hline \multicolumn{9}{|l|}{$\begin{array}{l}\text { Occupation } \\
\text { status }\end{array}$} \\
\hline student & $6(12)$ & $9(21.4)$ & 0 & 0 & $0.48(0.29-2.12)$ & $1.24(0.89-2.12)$ & 0.467 & 0.621 \\
\hline daily laborer & $8(16)$ & $5(11.9)$ & $3(37.5)$ & $2(40)$ & $1.73(0.64-2.64)$ & $1.01(0.64-2.64)$ & 0.374 & 0.554 \\
\hline merchant & $9(18)$ & $6(14.3)$ & 0 & $1(16.7)$ & $0.98(0.72-2.45)$ & $0.72(0.58-2.45)$ & 0.892 & 0.241 \\
\hline $\begin{array}{l}\text { governmental } \\
\text { employer }\end{array}$ & $10(20)$ & $7(16.7)$ & 0 & 1(14.3) & $2.21(1.98-4.78)$ & ) 1.91(0.98-2.68) & 0.188 & 0.836 \\
\hline farmer & $1(2)$ & $1(2.4)$ & 0 & 0 & $1.37(0.84-3.12)$ & $1.26(0.74-2.61)$ & 0.976 & 0.496 \\
\hline other & $16(32)$ & $14(33.3)$ & $3(18.8)$ & $3(21.4)$ & 1(Reference) & 1(Reference) & Reference & Reference \\
\hline \multicolumn{9}{|l|}{ Type of TB } \\
\hline ЕРТВ & $247(48.4)$ & $4(1.6)$ & $14(5.7)$ & $247(43.4)$ & $2.12(1.02-3.67)$ & 1.84(1.01-3.78) & 0.001 & 0.004 \\
\hline P.NEG & $20(3.9)$ & $3(2)$ & $4(20)$ & $207(35.6)$ & $1.66(1.21-2.87)$ & $0.47(0.24-2.71)$ & 0.003 & 0.021 \\
\hline P.POS & $243(47.6)$ & $4(2.9)$ & $6(2.5)$ & $138(25.4)$ & 1.00(reference) & 1 (Reference) & Reference & Reference \\
\hline \multicolumn{9}{|l|}{ Patient } \\
\hline \multicolumn{9}{|l|}{ Category } \\
\hline New & $465(91.2)$ & $564(96.9)$ & $20(4.3)$ & $9(1.7)$ & $1.67(1.26-3.89)$ & $0.98(0.38-2.19)$ & 0.161 & 0.651 \\
\hline Relapse & $19(3.7)$ & $3(0.5)$ & $1(5.3)$ & $1(33.3)$ & $0.91(0.78-3.2)$ & $1.28(0.76-1.72)$ & 0.739 & 0.892 \\
\hline Transfer In & $16(3.1)$ & $6(1)$ & $2(12.5)$ & $1(16.7)$ & $1.28(0.89-3.12)$ & $1.85(0.62-3.22)$ & 0.862 & 0.278 \\
\hline Other & $10(2)$ & $9(1.5)$ & $1(10)$ & 0 & 1.00(reference) & 1 (Reference) & Reference & Reference \\
\hline
\end{tabular}




\section{Chapter 4: Discussion}

Correct treatment of TB aims of curing patient, interrupting transmission of TB to other person and preventing bacilli from becoming drug resistant. As such insuring successful treatment completion might be required addressing multiple factors beyond simple supervision of drug intake [15-16]. In one of the health indicators of sustainable development goal is to bring the noncompletion of TB treatment below $10 \%$ in order to have treatment success of $85 \%$ for all detected smear positive cases [17-18]. Different studies showed that the currently running on DOTS strategy has increased treatment success rate. In Ethiopia national treatment success is $94 \%$ in 2017 [19].

Both sectors almost have the same catchment area. The present study revealed that within ten years duration private clinic gives anti-TB treatment coverage for 582 patients whereas governmental clinic gives for 510 patients. The treatment success rate of the private clinic is $98.1 \%$ which is 1.03 fold than the governmental health center (95.3\%). Governmental health center defaulting rate was triple fold of the private clinic $4.1 \%$ and $1.2 \%$ receptively, while the treatment failure of private clinic was $0.2 \%$, but no treatment failure in governmental health center. One a five year retrospective study showed in southern Ethiopia, the overall mean treatment success rate of the TB patients was 85.2\% [25]. Similar study shows in Mogadishu, Somalia successful treatment outcomes were $81.8 \%$ among TB patients in. Specific successful treatment outcomes included cured (61.6\%) and treatment completed (20.3\%). Specific unsuccessful treatment outcome included treatment failed (6.8\%), defaulters (6.2\%), transferred (2.9\%) and died (2.3\%) [22]. Also in Thailand Treatment outcomes were unsuccessful for 237 (33\%) patients in private facilities, and for respectively 1018 (23\%) and 655 (29\%) patients in small and large public facilities [23]. Available from: One study shows in Kampala, Uganda public clinics provided more appropriate care for tuberculosis patients than private clinics. Only one-third of the private clinics practiced a minimal standard of appropriate tuberculosis care. Public clinics are under the supervision of the Uganda NTLP, so their practices are standardized by the use of guidelines [20]. Similar results were reported from a study done in Korea [21]. (Figure 2).

In both sectors 15-49 years of age of patients had high treatment success rate, whereas children's didn't account defaulting rate. Males treatment success rate in both sectors were higher 
than the females $98.31 \%$ in private and $95.76 \%$ in governmental health center with their respective of $97.9 \%$ and $94.8 \%$ respectively. Whereas the defaulting rate of both sex in governmental sector is higher than the private sector $18.88 \%$ of females and $35.62 \%$ males with their respective $5.92 \%$ females and $14.3 \%$ males respectively. In both sectors the treatment success rate was higher with their educational level better, most of the defaulting patients were illiterate patients. Smear positive pulmonary TB prevalence in governmental health center was double higher than the private clinic, whereas the number of pulmonary negative TB patients of private clinic were 30 times folds of the governmental health center. This is due to lack of x-ray technology with untrained professional for further Tuberculosis diagnostic criteria. The success rate of smear pulmonary positive patients were almost the same, whereas smear negative pulmonary TB patients and EPTB treatment success rate was $98.6 \%$ and $98.3 \%$ in private clinic respectively which is higher than that of the governmental health center $80 \%$ and $94.3 \%$. One study in Tigray region, Ethiopia showed Out of the 407 PTB patients (221 males and 186 females) aged 15 years and above, $89.2 \%$ had successful and $10.8 \%$ had unsuccessful treatment outcome [24]. Newly diagnosed tuberculosis patient treatment success rate in the private clinic is higher than the governmental health center $98.5 \%$ and $95.7 \%$ respectively. While the defaulting rate after relapse of the disease in private clinic is $33.3 \%$ which is higher than the governmental health center $21.1 \%$ (Table 2).

Beside of Anti-TB treatment being free of payment this difference may be due to awareness about drug adherence also difference in socioeconomic status. This shows good progress of DOTS strategy and decrease of noncompliance in both sectors.

Age, educational level and the types of TB diagnosis with the treatment outcome of the patients were statistically significant $(\mathrm{p}<0.05)$ and associated in both sectors. While Sex, category of the patient and occupational status of the patients and their treatment outcome were not statistically significant $(\mathrm{p}>0.05)$. The literacy level plays greater role for treatment success rate. Hence the current study reviled the poor treatment outcome is observed in uneducated patients.

\section{(Table 3).}




\section{1: Conclusion}

The key to control TB is rapid detection and cure of infectious cases by TB control programmers. The public health priority of national TB control programmers is to work towards the objectives to treat successfully $85 \%$. Ensuring adherence to treatment is very important to achieve this priority [10]. According to the result of this study both sectors achieved the expected WHO targets by newly recommended strategy for TB treatment, DOTS and treatment success is much better to standard. This shows good progress of DOTS strategy and decrease of noncompliance in this area. Age, educational level and the types of TB diagnosis and treatment outcome of the patients were statistically associated in both sectors.

\section{2: Recommendation}

TB control program is adequate therefore this program should encourage and supported and continued in both sectors. Better counseling and awareness about the disease should have to be given for every anti-TB treatment receiving patients despite of their educational level and occupational status in both sectors. The extent of tuberculosis and its treatment burden is handled more in private clinic than the governmental health center, specially smear negative pulmonary TB which is 30 folds higher. This number indicate the second option to diagnosis tuberculosis is not well experienced, in turn tells us lack of the x-ray technology with well-trained health professionals. Beside of it needs a time and better economy, governmental health centers also recommended to fulfill the diagnostic material, like X-ray. The findings will act as baseline for further studies. 


\section{Abbreviation}

JMC - Jimma medium clinic

TB - Tuberculosis

JHC - Jimma health center

AIDS - Acquired immune deficiency syndrome

AFB - Acid-fast bacilli

ARI - Annual risk of TB infection

DOTS - Directly observed treatment of short course

EPTB - Extra pulmonary tuberculosis

HIV - Human immune deficiency virus

MDR-TB - Multi drug resistance tuberculosis

$\mathrm{MOH}$ - Ministry of health

PTB - Pulmonary tuberculosis

TLCP - TB and leprosy control program

PTB +ve - smear + ve pulmonary TB

PTB- ve - Smear - ve pulmonary TB

WHO - World health organization

NTCP - National tuberculosis control program

TLCP - TB and leprosy control program 


\section{Declaration}

\section{Ethical Approval and Consent to Participate}

I have received the ethical approval from Public Health Research Center, Tsinghua University, Beijing, china and mainly from Jimma Town health office, Jimma health center and from Jimma medium clinic with their respective TB treatment personnel's. Since it is secondary data, we didn't expect participants verbal approval.

\section{Consent for Publication}

Not Applicable

\section{Availability of data and materials}

It is secondary data. Hence, we don't have the consent from the patients, but the raw data is in my hand.

\section{Competing interests}

The authors declare that they have no competing interests

\section{Funding}

No funding was obtained for this study.

\section{Authors' Contributions}

EG analyzed and interpreted the patient data CF supervising over all of the study.

\section{Acknowledgment}

I would like to express my sincere and deep- rooted thanks for my advisors Professor Cheng Feng for his constructive advice, comments, guides and support. I would also like to thank all my friends who assisted me by providing necessary information. I would like to extend my gratitude to Tsinghua university for offering me this opportunity to do research thesis and for giving me broad band free internet service that aid me in data collection despite of the long distance. Finally, I would like to thanks Jimma city health office, Jimma health center, Jimma medium clinic with their respective TB treatment personnel's for their permission and cooperation for giving me a data. 


\section{Reference}

1. World Health Organization: Global Tuberculosis Control. 2011, Geneva: World Health Organization Google Scholar.

2. World Health Organization: Forty-fourth World Health Assembly. 1991, Geneva: World HealthOrganization, http://www.wpro.who.int/NR/rdonlyres/2DDF1ABF-8ACC-496F-B936ED01F81ACC0C/0/WHA445.pdf, Google Scholar

3. Raviglione MC, Pio A: Evolution of WHO policies for tuberculosis control, 1948-2001. Lancet. 2002, 359: 775-780. http://rih.stanford.edu/week\%204/Raviglione\%20\%20WHO\%20Policies\%20for\%20TB\%20Control.pdf,View Article PubMed Google Scholar

4. Lönroth K, Raviglione M: Global epidemiology of tuberculosis: Prospects for control. Semin Respir Crit Care Med. 2008, 29: 481-491. http://www.uptodate.com/contents/epidemiologyof-tuberculosis/abstract/2?utdPopup=true, View Article Google Scholar

5. World Health Organization: Global Tuberculosis Control. 2009, Geneva: World Health Organization,http://whqlibdoc.who.int/publications/2009/9789241563802_eng_doc.pdf, Google Scholar

6. Ali SA, Mavundla TR, Fantu R, Awoke T. Outcomes of TB treatment in HIV co-infected TB patients in Ethiopia: a cross-sectional analytic study. BMC Infectious Diseases. 2016; 16(1): 640. PubMed | Google Scholar

7. World health Organization, TB a global emergency, 16 ${ }^{\text {th }}$ years no 1, July-Aug 1993.

8. World Health Organization. The Stop TB Strategy: building on and enhancing DOTS to meet the TB-related Millennium Development Goals. 2006. Google Scholar

9. Ethiopian Health and Health Related Indicator 2017. 2009 EFY (2016/2017) (chapter 4, page 28)

10. Ethiopian Annual Performance Report 2017. health sector transformation plan-EFY 2009 (2016/17) version 1 (chapter 3, page 51)

11. Centres for Disease Control and Prevention, TB Elimination, Multidrug-resistant Tuberculosis (MDRTB)Factsheet; http://www.cdc.gov/tb/publications/factsheets/drtb/mdrtb.pdf) PubMed | Google Scholar

12. Jimma zonal health department, Jimma zone health report 2017.

13. Jimma town health office TB report center 2017. 
14. Veen J, Raviglione M, Rieder HL, Migliori GB, Graf P, Grzemska M, Zalesky R: Standardized tuberculosis treatment outcome monitoring in Europe. Recommendations of a Working Group of the World Health Organization (WHO) and the European Region of the International Union against Tuberculosis and Lung Disease (IUATLD) for uniform reporting by cohort analysis of treatment outcome in tuberculosis patients. Eur Respir J. 1998, 12: 505-510. http://erj.ersjournals.com/content/12/2/505.long, View Article PubMed Google Scholar

15. Narasimhan P, Wood J, MacIntyre CR, Mathai D. Risk factors for tuberculosis. Pulmonary medicine. 2013; 2013: 828939. PubMed | Google Scholar

16. Centers for Disease Control and Prevention. Plan to combat extensively drug-resistant tuberculosis: recommendations of the Federal Tuberculosis Task Force. Centers for Disease Control and Prevention. 2009; 58(3): 1-43. PubMed | Google Scholar

17. World Health Organization. Global tuberculosis report. 2016. Google Scholar

18. WHO annual Tb report 2017 http://www.who.int/tb/publications/global_report/en/

\section{PubMed | Google Scholar}

19. Ethiopian HSTP Final Print 2015. HSTP Health Sector Transformation Plan 2015/16 - 2019/20 (2008-2012 EFY) August 2015 (chapter 3, page 31)

20. Public and private providers' quality of care for tuberculosis patients in Kampala, Uganda research(https://www.ncbi.nlm.nih.gov/pmc/articles/PMC3419472/.PubMedGoogle Scholar

21. Hong YP, Kim SJ, Lee EG, Lew WJ, Bai JY. Treatment of bacillary pulmonary tuberculosis at the chest clinics in the private sector in Korea. Int J Tuberc Lung Dis. 1999;3:695-702. [PubMed]

22. Factors associated with tuberculosis treatment outcomes among tuberculosis patients attending tuberculosis treatment centers in 2016-2017 in Mogadishu, Somalia http://www.panafricanmed-journal.com/content/article/28/197/full/. PubMed | Google Scholar

23. Tuberculosis services and treatment outcomes in private and public health care facilities in Thailand, 2004-2006 (PDF Download Available). Available from: https://www.researchgate.net/publication/26319846_Tuberculosis_services_and treatment_o utcomes_in_private_and_public_health_care_facilities_in_Thailand_2004-2006PubMed $\underline{\text { Google Scholar }}$ 
24. Berhe G, Enquselassie F, Aseffa A. Treatment outcome of smear-positive pulmonary tuberculosis patients in Tigray Region, Northern Ethiopia. BMC public health. 2012; 12: 537. PubMed | Google Scholar.

25. Gebrezgabiher G, Romha G, Ejeta E, Asebe G, Zemene E, Ameni G. Treatment Outcome of Tuberculosis Patients under Directly Observed Treatment Short Course and Factors Affecting Outcome in Southern Ethiopia: a five-Year retrospective study. PloS one. 2016; 11(2): e0150560. PubMed | Google Schola

26. Successful TB treatment outcome and its associated factors among TB/HIV co-infected patients attending Gondar University Referral Hospital, Northwest Ethiopia: an institution based cross-sectional study. (https://www.ncbi.nlm.nih.gov/pmc/articles/PMC5299781/) PubMed | Google Scholar 
